\title{
Um estudo preliminar sobre o encontro entre a copesquisa e os science studies ${ }^{1}$
}

\author{
A preliminary study about the meeting between co-research \\ and science studies
}

\author{
CRISTINA DE AMORIM MACHADO \\ Universidade Estadual de Maringá | UEM
}

\section{BRUNO CAVA}

Universidade Nômade

\begin{abstract}
RESUMO Este artigo apresenta brevemente a copesquisa e os science studies, e faz uma análise inicial para uma possível parceria entre ambos, sobretudo no que diz respeito à circulação do conhecimento. Nosso objetivo é começar a esboçar um caminho conjunto para pensar a prática científica no Brasil; e sua justificativa é a relevância política de estreitar os laços entre ciência e sociedade no mundo contemporâneo.
\end{abstract}

Palavras-chave copesquisa - science studies - circulação do conhecimento.

\begin{abstract}
This paper briefly presents co-research and science studies. It is a first approach of the potential partnership between both of them, specially concerning with the circulation of knowledge. Our purpose is to trace a common path to analyze the scientific practice in Brazil; and we do that because we believe it is politically significant to deal with gathering science and society in the contemporary world.
\end{abstract}

Key words co-research - science studies - circulation of knowledge.

\section{Introdução}

Os saberes erigidos ao estatuto de ciência ao longo da história continuam gozando de considerável prestígio tanto do ponto de vista dos indivíduos isoladamente quanto numa perspectiva social. Podemos questionar a sua natureza, os métodos usados, os conceitos e objetos das ciências, a sua história, entre diversos outros pontos, mas decerto não questionaríamos os seus benefícios, por mais que, em alguns casos, saibamos exatamente o preço que estamos pagando. Também não questionaríamos a afirmação de que as ciências são feitas por mulheres e homens que se agrupam em instituições e comunidades científicas. Tendo em vista esse caráter coletivo, desde os anos 1960, especialmente depois de $A$ estrutura das revoluções científicas de Thomas Kuhn, ${ }^{2}$ passamos a considerar a negociação de uma série de compromissos entre os seus praticantes - como visões de mundo, metodologias e valores - para pensar as ciências. Essa negociação implica ação política. Em outras palavras, para entendermos o que é ciência, além de questões epistemológicas e metafísicas, temos de considerar as ético-políticas. Tal aspecto sociopolítico das ciências também 
foi destacado por Paul Feyerabend ${ }^{3}$ e é uma das premissas dos science studies e da copesquisa, que se interessam justamente pela prática científica, ou seja, pela ciência tal qual se faz. ${ }^{4}$

Os science studies são estudos com abordagens históricas, sociológicas e filosóficas acerca das ciências. Seu principal pressuposto é a ideia de que elas são práticas locais condicionadas social, material e culturalmente, contudo que também são capazes de atuar sobre e no contexto social em que estão inseridas. Sendo assim, a circulação do conhecimento - entendida aqui principalmente em quatro eixos: educação, produção, transmissão e divulgação ${ }^{5}$ - torna-se uma questão relevante tanto para a institucionalização da ciência como para a estruturação política de uma sociedade. Ademais, os praticantes dos science studies compartilham o duplo objetivo de, por um lado, sensibilizar os cientistas para as questões sociais e, por outro, aproximar os conteúdos científicos do grande público. Em ambos os casos, poderiam funcionar como uma ponte entre a ciência e a sociedade. ${ }^{6}$

A copesquisa, às vezes confundida com pesquisa-ação ou a pesquisa-intervenção, é uma metodologia militante que não separa teoria e prática, ambas se atravessam e se articulam entre si no interior dos sujeitos em luta e dentro de um processo mais amplo de organização política, autonomia produtiva e autovalorização. Tampouco trabalha com as noções tradicionais de sujeito e objeto, nem com a de intersubjetividade. Também não se confunde com a sociologia empírica, a antropologia estrutural ou qualquer relativismo pós-metafísico. 0 que há, para a copesquisa, com base em Foucault, Negri e no pós-estruturalismo, ${ }^{7}$ e tributária do materialismo marxista e spinozano, é produção de subjetividade, ativação de perspectivas que potenciam as transformações e recombinações das forças vivas, da criação de formas de vida, do viver como multidão de mundos. Desse ponto de vista, o sujeito é aberto e produz o real, quer dizer, há uma multiplicidade ontológica, e sua positividade reside em viver, resistir e reexistir. A ciência, logo, é tomada como uma prática, e os discursos é que organizam esse saber.

Veremos, a seguir, uma breve apresentação da copesquisa e dos science studies, como também os primeiros passos do que, acreditamos, pode vir a ser um bom encontro para pensar a produção e a circulação do conhecimento no Brasil.

\section{Science studies, uma leitura tupiniquim}

A partir dos anos 1960, novas imagens de ciência começam a entrar em cena. Uma delas foi veiculada pela chamada "nova filosofia da ciência", da qual se destacam alguns porta-vozes, como Thomas Kuhn, Imre Lakatos e Paul Feyerabend. ${ }^{8}$ Seu principal alvo era o positivismo lógico do Círculo de Viena e também o racionalismo crítico de Karl Popper, que propunham uma imagem de ciência fundamentalmente metodológica. ${ }^{9}$ Apesar de discordarem quanto ao método - indutivo e verificacionista para o primeiro, e hipotético-dedutivo e falseacionista para o segundo -, podemos tomá-los como representantes de um modelo normativo-demarcacionista de filosofia da ciência. Isto é, tanto para o positivismo quanto para Popper, o método científico, concebido como universal e atemporal, é o seu principal traço distintivo.

Em resposta a esse tipo de modelo, que produz uma imagem de ciência deveras restritiva, já que esta é um sistema complexo, muito mais do que um conjunto de teorias, uma prática metodológica ou um estoque de conhecimentos, Lakatos e Kuhn também propuseram modelos normativos, porém orientados historicamente, tentando contemplar um pouco mais da complexidade desse sistema. Em ambos, para entender a ciência há que se olhar retrospectivamente: em Lakatos, por meio de uma metodologia dos programas de pesquisa; e, em Kuhn, por intermédio dos paradigmas. ${ }^{10}$ Num sentido mais geral, uma voz totalmente dissonante foi a de Feyerabend, que também se opunha aos positivistas e a Popper, afirmando que não há critérios absolutos de cientificidade.

Ele favoreceu uma metodologia pluralista e mostrou a irracionalidade do racionalismo, desmistificando o suposto estatuto de superioridade da ciência. Assumiu, então, uma postura relativista, além de apontar para a questão da prática científica com todas as suas implicações políticas. ${ }^{11}$ 
Sob a influência da aproximação entre Filosofia e História da ciência, algumas instituições universitárias foram otimistas em relação à integração das duas áreas, criando vários departamentos e publicando diversos periódicos especializados. Por volta dos anos 1980, muitos já tinham desaparecido, acima de tudo porque havia incompatibilidade disciplinar, tendo em vista as diferenças intrínsecas à atividade historiográfica, notadamente extensiva e com foco no particular, e a filosófica, notadamente intensiva e baseada no universal. ${ }^{12}$ Além disso, ao longo dos anos 1970, alguns pesquisadores, grupos de pesquisa e instituições migraram da Filosofia da ciência para a Sociologia da ciência que, segundo Thomas Nickles ${ }^{13}$, tornou-se mais filosófica do que a História da ciência. Uma das principais vertentes desse movimento foi a Escola de Edimburgo, formada por Barry Barnes e David Bloor, entre outros. Esse grupo formulou 0 Programa Forte, ${ }^{14}$ que se caracteriza por atribuir às causas sociais a responsabilidade pela produção de crenças. ${ }^{15}$ Todavia isso significa que a ciência é determinada por causas sociais? A essa questão, ao contrário de Kuhn e outros, que responderiam apontando para a necessidade de uma nova noção de racionalidade para as ciências naturais, a Escola de Edimburgo responde "sim", as causas sociais são determinantes e estão sempre presentes.

É nesse contexto, a partir dos anos 1980, que se começa a falar em science studies. ${ }^{16}$ Esse movimento pretende ser interdisciplinar, agregando igualmente Filosofia, História e Sociologia da ciência, ainda que nem sempre de maneira equilibrada. ${ }^{17}$ Na percepção de Dominique Pestre, conquanto seja muito cedo para fornecer uma história mais abrangente, é possível identificar algumas características dos science studies: "A maneira como as questões têm sido estruturadas, os assuntos com os quais se têm lidado, a maneira como esses assuntos têm sido tratados e as pressuposições que suportam esses tratamentos". 18

Podemos dizer também, consoante Mendonça e Videira, ${ }^{19}$ que há algumas teses centrais compartilhadas entre os praticantes dos science studies: "A ciência é uma prática; a ciência experimental é independente da ciência teórica; a ciência é uma produção local, sendo, portanto, desunificada". Ou seja, ela não é só um conjunto de teorias; 0 experimento não é um mecanismo para confirmar ou refutar teorias, ele tem vida própria, no entanto com certeza pode articular-se com a teoria, ajustando-a ou ajustando-se; e a ciência se produz localmente, sendo que, evidentemente, os contextos locais podem ser multiplicados e compartilhados. Tanto na articulação entre teoria e experimento como no intercâmbio entre os diversos contextos locais podemos falar em circulação do conhecimento.

Algumas questões que se colocam são: 1) Quais são as diferenças dos science studies no que concerne às perspectivas anteriores? 2) Por que surgem os science studies? 3) Quais são seus problemas? 4) De que modo se pode colocar a questão da circulação do conhecimento na perspectiva dos science studies? 5) Como se pode fazer science studies no Brasil? Não pretendemos aqui responder a todas essas perguntas, elas exigem maior aprofundamento, entretanto apenas registrar a sua relevância, encaminhar uma primeira abordagem e prometer desenvolvê-las em trabalhos futuros.

Os autores dos science studies não se interessam por essa concepção normativista do positivismo lógico ou do racionalismo crítico, que, numa busca de critérios intrínsecos, levou a uma preocupação com a pureza da ciência, para livrá-la da metafísica. Ainda que não a defendam explicitamente, a metafísica não é problema para os science studies, que também tentam eliminar qualquer proposta dicotômica, como internalismo/externalismo, universal/particular e realismo/construtivismo. ${ }^{20}$

Por outro lado, a história que eles praticam não tem função de legitimação, já que não acreditam que a identidade e a legitimidade passaram a ser conferidas pela História. Os objetos científicos são enfatizados, não "a" ciência. Um dos livros organizados por Lorraine Daston, por exemplo, chama-se Biographies of scientific objects, quer dizer, os objetos científicos têm biografias, são efêmeros, mudam ao longo do tempo. Aqui a discussão problematiza a clássica dicotomia sobre a objetividade científica: de um lado, o realismo, com seus objetos naturais, reais e eternos; de outro, o construtivismo, com seus conteúdos culturais, históricos e efêmeros. Os science studies oferecem uma alternativa a essa dicotomia, propondo que os objetos científicos possam ser ao mesmo tempo reais e históricos. ${ }^{21}$ Certamente que ser real aqui não implica preexistência ou permanência, mas sim a concretude e a materialidade da experiência, isto é, partindo de uma ênfase nas práticas, nas histórias e linguagens locais, revela-se a teoria numa nova perspectiva. 
Dessa maneira, é possível afirmar que os science studies têm se dedicado a entender a prática científica, afastando-se de uma concepção universal de ciência e aproximando-se das circunstâncias locais em que ela se realiza. É nesse sentido que se vê o interesse de Peter Galison pela historiografia local, que se caracteriza por instabilidade, hibridização e zonas de troca linguísticas, considerando a diversidade de entendimentos dos conceitos e objetos científicos: "Nos science studies havíamos adquirido uma importante perspectiva devido ao facto de nos concentrarmos em circunstâncias locais". ${ }^{22}$ Diante disso, parece-nos natural e mesmo necessário falar em circulação da ciência, já que, embora o conhecimento científico seja produzido num cenário local, ele tem a capacidade de mover-se de um cenário para outro.

A Sociologia da ciência, por sua vez, de movimento "libertador" tornou-se um programa a ser tratado com cuidado, tendo em vista os reflexos políticos de suas teses radicais, que conduzem ao relativismo cultural. Até mesmo Feyerabend, em sua autobiografia, reconhece esse problema do relativismo, chegando "à conclusão de que toda cultura é potencialmente todas as culturas, e que as características culturais específicas são manifestações mutáveis de uma única natureza humana". ${ }^{23}$ Talvez fosse melhor complementar, sob a ótica de Edward Said, que "todas as culturas estão envolvidas uma na outra; nenhuma é única e pura, todas são híbridas, heterogêneas, extraordinariamente diferenciadas e não monolíticas". ${ }^{24}$

0 problema do relativismo científico, ou seja, da não existência de critérios intrínsecos à ciência que nos conduzam a uma escolha racional, universal e atemporal, leva-nos à seguinte questão de ordem política: como justificar a ciência da maneira usual, com pretensões de verdade, universalidade e neutralidade, numa sociedade democrática e plural que produz as mais diversas narrativas científicas? Nesse aspecto, muitos especialistas dos science studies descartam qualquer tese que considere a ciência uma empreitada totalmente racional, progressiva ou de obtenção da verdade. ${ }^{25}$ 0 que não significa que sejam libertários ou revolucionários.

Na visão de Mendonça e Videira, ${ }^{26}$ para além de não serem revolucionários e apesar de acharem-se inovadores em vários sentidos, os science studies acabam dando suporte ao status quo por tratarem assimetricamente a relação entre ciência e sociedade, dando mais ênfase à primeira, e separando o mundo dos especialistas e o dos leigos. Isso, decerto, seria um impeditivo para o encontro com a copesquisa, que, como veremos mais adiante, tem como premissa a ação política revolucionária. Afora esse obstáculo, acreditamos que é possível potencializar algumas ferramentas dos science studies, sobretudo no seu viés feyerabendiano, para viabilizar essa parceria. Isso sem esquecer, de acordo com Araújo; Mendonça e Videira, ${ }^{27}$ que Feyerabend também guarda algo de conservador ao defender a autonomia da ciência; mas ele chama a atenção para a obrigação de defender as tradições consideradas não científicas. Num contexto de ciência periférica, como é o caso do Brasil, essa perspectiva torna-se bastante eloquente.

Podemos dizer, por isso, que os science studies acabam por constituir uma agenda político-pedagógica que se preocupa com o problema, já colocado por Feyerabend, de como fazer ciência na democracia, e tentam dar conta dessas implicações científicas no regime democrático. A questão que se segue é: Se a ciência é de fato constituída localmente, como pode ser universal ou compartilhada? Em outras palavras, como lidar com o contingente, com as diferenças e com o particular num regime democrático e universal? 0 que, evidentemente, não é um problema restrito à prática científica. Nesse cenário, a relação entre ciência e sociedade muda drasticamente, ${ }^{28}$ e como vemos nos science studies, não se pode mais prescindir do contexto político para discutir essa relação.

Como já foi analisado anteriormente, não obstante a concepção de ciência dos science studies ser mais rica do que as anteriores, ainda há muito que se fazer no que se refere à sua visão de sociedade:

A Filosofia da ciência deveria auxiliar nesse novo estado de coisas com sua normatividade negativa, isto é, com seus instrumentos da atitude crítica e reflexiva, bem como com sua visão de conjunto, no sentido de nos ajudar a sermos coerentes com os princípios epistêmicos e societais instituídos por nós mesmos, ao menos enquanto eles vigirem, de modo a podermos construir juntos, especialistas e leigos, um bom mundo comum para se viver uma vida feliz. ${ }^{29}$ 
Essa citação nos leva de volta às preocupações de Feyerabend, que não eram "nem a racionalidade, nem a ciência, nem a liberdade - abstrações como essas causaram mais mal do que bem -, e sim a qualidade das vidas dos indivíduos" ${ }^{30}$ Acrescentaríamos aqui também mais um caminho possível para dar conta dessa assimetria no tratamento da relação entre ciência e sociedade: a copesquisa. Como veremos na próxima seção, suas origens se encontram exatamente em movimentos sociais.

Interessa-nos um ponto específico e que consideramos nevrálgico para entender essa relação entre ciência e sociedade: a circulação do conhecimento. Soa um pouco dramático, porém de fato o é, se considerarmos, por exemplo, o recente suicídio de Aaron Swartz. ${ }^{31}$ Preso em 2011 por baixar milhões de artigos acadêmicos via rede do MIT, Swartz pagou fiança e foi liberado, contudo estava em meio a um processo - o MIT saiu de cena, todavia o governo de Massachussets continuou - que poderia resultar em 35 anos de prisão além de multa milionária. No entanto ele surpreendeu o mundo com o seu suicídio no dia 11 de janeiro de 2013 aos 26 anos de idade. 0 que estava em jogo nesse triste caso era exatamente o problema da circulação, com suas várias facetas extremamente contemporâneas: regulação da internet, direitos autorais, acesso ao conhecimento, ciberativismo, software livre, entre outras.

Vale lembrar que estamos cientes de algumas críticas à noção de circulação do conhecimento, como a de Peter Dear, por exemplo, que a considera inadequada, tendo em vista o modelo econômico de circulação, que explica como a troca produz riqueza. ${ }^{32}$ Para ele, o que há na ciência é distribuição ou proliferação, e seria preciso uma analogia muito forte com o dinheiro e a riqueza para fazer esse conceito funcionar para o conhecimento científico. Apesar dessa objeção, acreditamos que a ênfase na circulação pode ser uma maneira de integrar as mais diversas narrativas a respeito da ciência; mas a circulação não deve ser entendida como o resultado de alguma característica intrínseca de um conhecimento universal. Ao contrário, entendemos que a circulação do conhecimento é um fenômeno a ser analisado não apenas do ponto de vista do deslocamento geográfico, entretanto também de mudanças epistemológicas, filosóficas e políticas que resultam das trocas culturais.

No caso do Brasil, que se trata, em geral, de um ator coadjuvante na cena científica internacional, essa questão torna-se ainda mais importante, quer seja pelo viés da educação, da produção, da transmissão ou da divulgação da ciência. Talvez urgente, se considerarmos o alardeado crescimento econômico brasileiro, que acaba por produzir um imparável discurso sobre a inovação, além da continuada (re)produção do modelo de big science, que encontrou abrigo no projeto do Brasil Maior, como veremos na próxima seção.

Vale lembrar também o seguinte ponto: a ciência, no Brasil, ao contrário de outros países, é produzida principalmente em instituições públicas, o que agrava ainda mais a questão do equilíbrio entre democracia e produção científica. Afinal, não são tão frequentes os casos, como o de Miguel Nicolelis, neurocientista brasileiro que frequentou recentemente as páginas de vários jornais por causa do seu experimento de "computação orgânica" ${ }^{33}$ Esse caso chama a nossa atenção por vários motivos: é obra conjunta de várias universidades sem fins lucrativos; seus resultados têm sido publicados em periódicos de livre acesso; essa e outras pesquisas do grupo são direcionadas para fins de cooperação e diminuição das desigualdades; entre outros. Todos os motivos citados, e também o próprio objeto de pesquisa - apelidado de brainet -, dizem respeito ao trabalho coletivo, cooperativo e em rede, isto é, se referem à circulação do conhecimento.

Para finalizar esta seção, gostaríamos de salientar que, embora não concordemos com a derradeira frase de Mendonça e Videira de que, na perspectiva pluralista dos science studies, a ciência deveria ser entendida como milagre, tendo em vista que não são explicitados os fatores externos que a influenciam e os critérios sobre como ela deve ser feita, concordamos com as suas duas conclusões, dentre elas: os science studies "não servem como base para 0 desenvolvimento da ciência em países menos desenvolvidos como o nosso". ${ }^{34}$ Mas a pergunta que podemos lhes fazer é: por que deveriam servir? Os science studies têm que ser normativos para ter alguma função? Será que o seu papel de ponte entre ciência e sociedade já não é o bastante?

Não nos parece que o Brasil ou qualquer outro país deva seguir uma cartilha acerca de como fazer ciência, quer seja escrita pelos science studies, pela Filosofia da ciência ou qualquer outra disciplina. 0 fato é que a ciência já se faz 
e os science studies colaboram para um entendimento sobre essa prática. Isso nos parece uma grande contribuição. Mas vejamos agora um pouco mais dessas questões locais tratadas pela copesquisa.

\section{Pensando a copesquisa no Brasil}

No refluxo da crise econômico-financeira mundial, tem-se a sensação, multiplicada muitas vezes pela propaganda oficial, que o Brasil vive o seu melhor momento. 0 governo federal anuncia a erradicação da pobreza e adota como slogan: "país rico é país sem pobreza". 0 governo assume o "social" como prioridade, associando o discurso do desenvolvimento com o da inclusão. 0 programa consiste em converter um país fraco de pobres em um país forte de classe média, realizando um itinerário histórico-político que remonta à era Vargas, aos estudos da Comissão Econômica para a América Latina e o Caribe e o consenso, da esquerda à direita, sobre o desenvolvimento nacional. É como se o Brasil não fosse mais o país do futuro que nunca se realiza, entravado pelos arcaísmos do subdesenvolvimento, porém agora desbloqueado por uma renovação administrativa e empresarial como nunca antes vista. ${ }^{35}$

Nesse contexto se destaca a preocupação em modernizar o país em todos os níveis. Se a economia global contemporânea valoriza a produção imaterial, em que o maior patrimônio está nos recursos cognitivos e intelectuais, ${ }^{36}$ é preciso investir muito em tecnologia, pesquisa e ciência; capacitar os recursos humanos e incentivá-los a produzir pelo país; em termos feyerabendianos, é preciso fazer a "conquista da abundância" ${ }^{37} 0$ Plano Brasil Maior, do governo federal, exprime essa vontade de tirar o parque tecnológico brasileiro da condição de defasagem, assegurando uma inserção no cenário internacional. Aqui, a máxima governamental é "inovar para competir, competir para crescer", ${ }^{38}$ articulando como eixos do discurso a inovação, a competitividade e o crescimento econômico. 0 estado brasileiro se coloca, assim, como princípio da unidade da produção científica, dirigida às imperiosas necessidades nacionais do desenvolvimento técnico-científico. A premissa e a finalidade da inovação passam a ser referenciadas ao âmbito nacional. A inovação está, por isso, no coração dos interesses nacionais que o estado enuncia, apesar das profundas divisões e assimetrias que persistem no núcleo do "processo civilizatório" que o discurso do desenvolvimento nacional representa. Seu fundamento é um capitalismo científico, racionalizado pelos valores emergentes da eficiência de gestão, sustentabilidade, empreendedorismo, consciência socioambiental e tantos quantos forem os "conceitos de pacificação" que se queiram impingir a esse processo. Novamente, em termos de Feyerabend, ${ }^{39}$ trata-se de uma "admirável monotonia nova".

A questão que se coloca é: De que maneira pensar a produção científica fora do padrão majoritário voltado ao desenvolvimento nacional, em extemporânea aplicação das teorias da modernização do pós-guerra? ${ }^{40}$ Como pensar a inovação de modo a expressar a multiplicidade nas bases da composição social? Quer dizer, segundo as forças minoritárias que não somente compõem a maioria quantitativa, como também qualitativamente a determinam de múltiplos modos. Essas determinações internas das minorias são irredutíveis à homogenização sem perder a sua qualidade destoante do modelo. E é nessa imensurabilidade que se distingue uma concepção forte de diferença e uma que a anule no caldo homogêneo da diversidade cultural. Ou seja, que a achate num multiculturalismo onde sempre é possível conviver com as diferenças, desde que segundo a matriz da modernidade: jurídica e politicamente estatocêntrica, axiologicamente eurocêntrica e, acima de tudo, capitalista. Pode o cientista escapar dessa métrica mercadológica, dos critérios eurocêntricos e mediados pelo estado, na sua atividade de produção de conhecimento? É conhecida a figura do cientista à sombra do poder estatal, eticamente dobrado pelas "novas oportunidades" que se descortinem em tempos de crescimento econômico e fortalecimento estatal. A que preço ser competitivo, certificando-se dos novos critérios de julgamento e remuneração? Pode o cientista do século XXI aspirar a não sucumbir à corrente, e ser mais que mero delfim a serviço de objetivos e lógicas que a ele se impõem?

É aí que a copesquisa, como pesquisa implicada e militante, responde: sim, ele pode. Engendrada inicialmente no autonomismo operaísta italiano dos anos 1970, ${ }^{41}$ no longo período do "maio de 1968 italiano", a copesquisa encon- 
trou sua experiência fundante na riquíssima vivência do pesquisador junto a movimentos sociais, rádios comunitárias e livres, redes de militância cultural, ocupações urbanas, arte de rua, ateliês populares, lutas dos negros, mulheres, imigrantes, LGBT e denso etcétera. É nesse mergulho na produção local, que implica agenda política e circulação do conhecimento, que acreditamos poder promover o encontro entre copesquisa e science studies. Alguns conceitos nos parecem especialmente propícios a essa junção. Dois já foram citados anteriormente, as zonas de troca (Peter Galison) e as biografias de objetos científicos (Lorraine Daston), contudo há que se incluir também a teoria ator-rede, de Bruno Latour, que talvez seja o que mais viabiliza a aproximação que aqui se propõe. Seus conceitos de tradução, híbrido e coletivo, entre outros, podem ser chaves para pensar a circulação do conhecimento. ${ }^{42}$

A copesquisa não deve ser encarada como ainda outra metodologia à disposição na prateleira epistemológica. Como pesquisa "implicada", a copesquisa é também um modo de vida. 0 pesquisador atua como um ator, na junção dos eventos históricos e conflitos políticos de seu tempo, engajando-se no drama. Nesse perspectiva, a copesquisa não encontra critério de validade na objetividade científica, que se elabore mediante a depuração sistemática da subjetividade, como filtro para a produção do conhecimento. Como se existisse uma massa disforme de dados em estado pré-científico, apenas aguardando a chegada do cientista genial, credenciado pela instituição e munido de método consagrado, para elevar esse "empírico selvagem" à condição de ciência.

Não se trata, por conseguinte, de outra versão da domesticação da natureza, "natureza natural" ou social, por meio da razão ordenadora, classificadora, razão confiável e certificada pela norma científica. A copesquisa desde 0 princípio recusa essa normatividade científica conformada à estrutura social da modernidade. Nesse cânon, os rituais, credenciamentos e cultos, os critérios de aceitação, circulação e consagração que definem a validade científica carecem do grau de implicação exigido no pesquisar-com. Ao assumir a condição de copesquisador, passa-se a questionar a própria fonte de valor dos valores dados quando se fala em ciência ou inovação, seja o credenciamento do estado, do mercado ou de alguma concepção normativa de ciência (íntima aos dois primeiros). Assim, como primeiro elemento, a copesquisa não faz apelo à objetividade. Ainda que se refira à objetividade renovada, mitigada ou relativizada, cuja validação se dê no interior de malhas institucionais e suas instâncias judicativas. Esta "vontade de objetivação" nas metodologias, ao fim e ao cabo, presta contas à estrutura social de que os métodos são, em primeiro lugar, instituições e salvaguardas. A copesquisa, ao contrário, se compromete com a multiplicidade em que se implica e do que se exprime em processo diferencial, situando-se essencialmente no campo da produção de subjetividade. ${ }^{43}$

Isto é, se tradicionalmente os positivismos tentam reduzir a intencionalidade ao mínimo, cristalizando saberes e perseguindo o pesquisador neles - removendo, destarte, a carga insubmissa de variação e imprevisibilidade das coisas e pessoas -, aqui se perscrutam as subjetividades em estado movente, a máxima intencionalidade: a franja de constituição de outros mundos, formas de vida, de relacionar-se, produzir e conviver. Os saberes não compilam nunca um corpus. Os saberes vivos reinventam-se sucessivamente, estão baseados na variação contínua que é própria do processo de diferenciação da vida. Nos termos de Feyerabend:

A ciência como empreendimento vivo (ao contrário de ciência como um "corpo de conhecimento") é parte da história. As fórmulas que adornam nossos manuais são partes temporariamente congeladas de atividades que se movem com o fluxo da história. É preciso que sejam descongeladas, conectadas uma vez mais ao fluxo a fim de que sejam compreendidas e produzam resultados. ${ }^{44}$

Desdobrando um pouco mais, trata-se de uma antropologia das transformações, em que o caso não é tanto compreender a natureza da variação, todavia a variação como natureza, ${ }^{45}$ como ensina o perspectivismo ameríndio de Eduardo Viveiros de Castro. Noutras palavras, na copesquisa amerindianizada: em vez de despir o conhecimento de subjetividade, aspirando a uma (impossível e sempre interessada) universalidade, situá-lo, territorializá-lo de modo tão saturado de determinações e qualidades, tão processualmente dinâmico, tão apaixonado, que não haja nada, nenhuma coisa nem pessoa, que não possa ser ativado como sujeito, quer dizer, como ponto de vista e centro de intencionalidade com que se constitui o mundo. 
Neste ponto, o leitor pode estar se inquirindo se a copesquisa não passa de mais outra Grande Ideia, outro modismo intelectual com parfum de scandale. Mas, então, com quem se faz a pesquisa na copesquisa? Que tipo de mecanismo de responsabilidade e responsabilização poderia possuir um processo de conhecimento? Quais são seus critérios?

De fato, o copesquisador não pretende prestar contas de seu trabalho a entidades oficiais de pesquisa e assemelhados, já que sua proposta é autonomista. Por outro lado, não pode deixar de assumir uma ética, uma responsabilidade em relação às causas e consequências de sua pesquisa. A libertação no tocante às injunções do estado, do mercado e da ciência normativa que lhes serve não significa o relativismo. Isso seria novamente nivelar todas as diferenças no pano de fundo de um pós-modernismo fraco, que não serviria senão de mais uma apologia do presente. A copesquisa, afinal, contrapõe-se aos multiculturalismos que, pela via transversa, guarnecem o jogral do estado presente das coisas.

Para contornar esse risco de neutralização, o copesquisador precisa situar-se onde acontecem as diferenças, os devires minoritários, nas coordenadas de tempo e espaço do trabalho vivo. ${ }^{46}$ As diferenças determinam um transbordamento no que diz respeito à lógica homogênea e unificadora de uma ciência matizada pelo estado e pelo mercado. 0 desenvolvimento, qualificado pelas diferenças, não somente desborda, epistemicamente, da matriz da modernidade capitalista; como também embute, no plano político, um antagonismo ao sistema político-econômico vigente. Talvez mais apropriado seja chamá-lo reenvolvimentismo intensivo, como prefere Viveiros de Castro. ${ }^{47} \mathrm{De}$ qualquer maneira, 0 antagonismo se determina em virtude das diferenças, estas que espessam alternativas de cooperação social e que concretizam, aqui e agora, um conhecimento liberto das mediações estatais e mercadológicas.

0 conhecimento, pois, emerge de sujeitos em luta contra o modelo majoritário, e que lutam, exatamente, não porque se definam por ser anti ou contra o poder constituído. Mas, sim, porque se definem e vivem por uma positividade, uma alternativa latente na dupla face ética e política, e sobre a qual apóiam todas as ações de recusa e negatividade. A copesquisa se implica, nessa positividade, como parte dos mecanismos e redes de produção de alteridade ao status quo. Nesse sentido, pode-se dizer que a copesquisa participa de uma "ontologia crítica do presente" ${ }^{48}$ nos termos de Michel Foucault, bem como também serve para ativar os saberes menores, clandestinos, interditados, desqualificados pelo funcionamento da estrutura institucional da ciência normal e normatizada. ${ }^{49}$ Com a diferença que sejam saberes vivos, atuantes no presente, furando-o de determinações autônomas e qualidades criativas suprimidas. Daí que não se possa falar em copesquisa descolada nem de uma autonomia produtiva - em relação ao estado, ao mercado, suas lógicas e métricas - nem de um impulso de organização dos nós e minorias que se diferenciam da "admirável monotonia nova" feyerabendiana. Ou seja, trata-se de organização simultaneamente ética e política. ${ }^{50}$

Copesquisar envolve, portanto, descer às condições de pobreza, que é entendida aqui não só como situação de privação e sobrevivência, como também de potência, liberdade e autonomia radicalizadas pela própria circunstância na produção de vida. Nos termos de Marx, em passagem conhecida dos Grundrisse: "0 trabalho como pobreza absoluta: a pobreza não como falta, mas como completa exclusão da riqueza objetiva. (...) 0 trabalho não como objeto, mas como atividade; não como valor, como fonte viva do valor" ${ }^{51}$ Noutras palavras, não se pode deixar de levar em consideração as formas criativas da cooperação e da imaginação nas condições de pobreza, pensada como lugar de máximo existencial, onde 0 ambiente abunda de estímulos, constrições e paixões. A copesquisa não hesita em associar-se por dentro das redes produtivas da pobreza, em busca das diferenciações, devires e antagonismos latentes, que paulatinamente se auto-organizam e galgam autonomia. Como disse Feyerabend, está na hora "de nos aproximarmos daqueles que supostamente irão lucrar com nossas ideias, como se fôssemos ignorantes precisando de instrução, (...) e não como os maiores presentes que o céu já enviou para os Pobres, Enfermos e Ignorantes" ${ }^{52}$ Se 0 terceiro mundo contém uma bomba-relógio, uma insubmissão essencial em referência aos esquemas obsessivos da modernização, é porque essa composição na pobreza não se deixa neutralizar e capturar facilmente. É preciso pesquisar o que, entre os pobres, é usina de potência do conhecimento. 


\section{Considerações finais: o encontro entre science studies e copesquisa}

Será possível uma colaboração entre science studies e copesquisa para pensar a circulação do conhecimento? Será produtiva no sentido de criar novas possibilidades de ação e reflexão? Qual é a contribuição dos science studies para a copesquisa e vice-versa? Pode ser prematuro tentar responder a essas questões nesse momento, tendo em vista que se trata de um estudo preliminar. Com certeza não pretendíamos aqui ser exaustivos, tampouco formular alguma novidade metodológica. Ainda há um caminho longo a ser percorrido para tecer os fios soltos, então, por ora, demos apenas os primeiros passos.

Como vimos, há alguns pontos em comum entre science studies e copesquisa, que, acreditamos, podem ajudar a pensar a ciência entre nós e, consequentemente, a fazer ciência no Brasil. Destacamos aqui o foco na prática científica, a relação entre ciência e política, a interdisciplinaridade, bem como a articulação entre teoria e prática. Constatamos também que a copesquisa pode ajudar a diminuir a assimetria entre ciência e sociedade detectada nos science studies, que parecem dar mais ênfase à primeira. As ideias de Feyerabend nos ajudaram a construir essa aproximação. Algumas delas, como a de autonomia da ciência, são cruciais nesse encontro entre copesquisa e science studies, no entanto demandam mais aprofundamento. Outras questões, como a relação entre homem e natureza, a representação e a propriedade intelectual não foram propriamente discutidas aqui, entretanto serão desdobradas em trabalhos futuros, tendo em vista a sua relevância para pensar a ciência tanto no âmbito dos science studies quanto da copesquisa.

Podemos dizer que a noção de ciência é solidária à de circulação, que a ciência é processo e produto de cooperação e que, por isso, a circulação é automaticamente produtiva. É ela que gera as ciências, pois coordena transversalmente os vários níveis de pesquisa e análise (do "campo" às instituições consagradas, ao jornalismo científico, ao complexo industrial-militar, da cura da AIDS aos conhecimentos indígenas), que implicam tanto a educação como a transmissão e a divulgação das ciências. A forma de cooperação é que determina o tipo de ciência em sua relação com o "dentro" e o "fora", ou a maneira com que traça essa e muitas outras distinções normativas. Se pensarmos em descrever como de fato a ciência ocorre, não haveria como contornar, por exemplo, a expropriação dessa cooperação (que extrapola a dita "comunidade científica"), bem como o fato de que, de dentro da cooperação, de baixo pra cima, também muda a própria maneira de colaborar e produzir conhecimento. A circulação produz ciência e vice-versa.

Nesse percurso foi possível perceber, para além de semelhanças e dessemelhanças, que o esforço para adentrar em outras searas com as quais estamos pouco acostumados pode ser revelador sobre aquilo que nos é habitual. Nesse aspecto, o "pesquisar com" da copesquisa apresenta-se como uma forte parceria para a "ciência tal qual se faz" dos science studies, sobretudo no que diz respeito à questão da circulação do conhecimento. Afinal, ambos entendem as ciências como saberes vivos que circulam e se transformam constantemente.

\section{Notas e referências bibliográficas}

Cristina de Amorim Machado é bacharel em Filosofia pela UERJ, mestre em Filosofia pela PUC-Rio e doutora em Letras pela PUC-Rio. Atualmente é professora adjunta do Departamento de Fundamentos da Educação (área de Metodologia de Pesquisa) da Universidade Estadual de Maringá. E-mail: cristina_machado@ yahoo.com.

Bruno Cava é bacharel e mestre em Direito pela UERJ, faz parte da rede Universidade Nômade, coedita as revistas Global Brasil (1415-8604) e Lugar Comum (ISSN/1415-8604), e publica o blogue Quadrado dos loucos (disponível em: <http://quadradodosloucos.com.br>). E-mail: hamletvictrix@hotmail.com. Os autores agradecem aos pareceristas da revista pelos comentários.

1 Optamos por não traduzir science studies, que também têm sido chamados de social studies of science (SSS) ou science, technology and society studies (STS), por não considerarmos adequadas algumas das possíveis traduções. Não se trata de "estudos de ciência", e "estudos sobre a ciência" parece demasiado genérico. Como destacamos, a multidisciplinaridade dos science studies, também não nos parecem apropriadas as denominações "estudos sociais da ciência", "história social da ciência" ou "história cultural da ciência". Tampouco se trata de uma Filosofia da ciência. Diante desse impasse e por falta de melhor opção, por ora manteremos a denominação science studies. 
Toda a obra de Feyerabend aborda a ciência nessa perspectiva política. Como referência, será citado apenas o seu livro mais conhecido, Contra o método, que foi publicado em três edições revistas pelo autor ao longo de 20 anos, e das quais dispomos de duas traduções brasileiras, uma da primeira edição e outra da terceira. FEYERABEND, Paul. Contra o método. Tradução de Octanny S. da Mota e Leonidas Hegenberg. 1. ed. Rio de Janeiro: Francisco Alves, 1989; Idem, ibidem. Tradução de Cezar Augusto Mortari. 3.ed. São Paulo: Editora Unesp, 2007.

Um dos poucos livros de autores dos science studies traduzidos para o português chama-se justamente $A$ ciência tal qual se faz. Trata-se de uma coletânea com textos de Bruno Latour, Peter Galison e Lorraine Daston, et al. Cf. GIL, Fernando (Org.). A ciência tal qual se faz. Lisboa: Edições João Sá da Costa, 1999.

A questão da circulação do conhecimento e esses quatro eixos serão aprofundados em trabalhos posteriores, mas remetemos o leitor a algumas referências sobre 0 assunto: BIAGIOLI, Mario; GALISON, Peter. Scientific authorship: credit and intellectual property in science. Nova lorque: Routledge, 2003; MONTGOMERY, Scott. Science in translation: Movements of knowledge through cultures and time. University of Chicago Press, 2002; MACHADO, Cristina. 0 papel da tradução na transmissão da ciência: o caso do Tetrabiblos de Ptolomeu. Rio de Janeiro: MauadX, 2012; SECORD, James. Knowledge in transit. Isis, 95, p. 654-672, 2004; GUIMARÃES, Eduardo (Org.). Produção e circulação do conhecimento: estado, mídia e sociedade. Campinas: Pontes, 2003; CAVROGLU, Kostas. The ideology of popularization and the popularization of ideology: Some issues for the History of Science. Revista Brasileira de História da Ciência. Rio de Janeiro, v. 5, n. 2, p. 224-231, jul.-dez./2012.

6 Uma obra de referência da área é: BIAGIOLI, Mario (Ed.). The science studies reader. Routledge, 1999. Esse livro, que também é uma coletânea, foi dedicado a Paul Feyerabend, o que é mais um indicativo da influência de Feyerabend nos autores dos science studies. De autores brasileiros, só para citar alguns: ARAUJO, P.; MENDONÇA, A.; VIDEIRA, A. Primazia da democracia e autonomia da ciência: 0 pensamento de Feyerabend no contexto dos science studies. Filosofia Unisinos, 11(1), jan./abr. 2010; MENDONÇA, André. Por uma nova abordagem da interface ciência/sociedade: a tarefa da Filosofia da ciência no contexto dos science studies. Tese (Doutorado em Filosofia), UERJ, 2008; MENDONÇA, André; VIDEIRA, Antonio. Instituindo os science studies. Episteme, Porto Alegre, n. 19, p. 149-158, 2004; Idem. Contextualizing the contexts of discovery and justification: how to do science studies in Brazil. In: KRAUSE, Décio; VIDEIRA, Antonio (Ed.) Brazilian studies in Philosophy and History of Science. Springer, 2011; e VIDEIRA, Antonio. Filosofia da ciência sob o signo dos science studies. Abstracta, Niterói, v. 2, p. 70-83, 2005.

7 Só para citar alguns títulos: ALQUATI, Romano. Per fare conricerca. Turim: Velleità Alternative, 1993; GUATTARI, Felix; NEGRI, Antonio. New lines of alliance, new spaces of liberty. Nova lorque: Autonomedia, 2010; NEGRI, Antonio; COCCO, Giuseppe. Glob(AL): biopoder e luta em uma américa latina globalizada. Tradução de Eliana Aguiar. Rio de Janeiro: Record, 2005; NEGRI, Antonio; HARDT, Michael. Multidão: guerra e democracia na era do império. Tradução de Clóvis Marques. Rio de Janeiro: Record, 2006.

8 As obras mais conhecidas de Kuhn e Feyerabend já foram mencionadas em notas anteriores. De Lakatos, destaca-se o texto: LAKATOS, Imre. 0 falseamento e a metodologia dos programas de pesquisa científica. In: LAKATOS, Imre; MUSGRAVE, Alan (Org.). A crítica e o desenvolvimento do conhecimento. São Paulo: Cultrix/EDUSP, 1979. Esse texto também aparece numa edição portuguesa: LAKATOS, Imre. Falsificação e metodologia dos programas de investigação científica. Tradução de Emília Picado Tavares Marinho Mendes. Lisboa: Edições 70, 1999.

Cf. HAHN, Hans; NEURATH, Otto; CARNAP, Rudolf. A concepção científica do mundo. Cadernos de História e Filosofia da Ciência, São Paulo, n. 10, p. 5-20, 1986; e POPPER, Karl. A lógica da pesquisa científica. Tradução de Leonidas Hegenberg e Octanny Silveira da Mota. São Paulo: Editora Cultrix, 1975.

10 Os programas de pesquisa lakatosianos são tributários em grande medida da sua análise dos modelos de Popper e de Kuhn. Vale lembrar que Lakatos considerava o modelo de Kuhn problemático, tendo em vista que a adesão a um paradigma não se explica racionalmente. Essa discussão é mais desenvolvida em: MACHADO, Cristina. Laudan, a Sociologia da ciência e a questão da demarcação. In: VIDEIRA, Antonio (Org.). Novas perspectivas em Filosofia da ciência. Rio de Janeiro: EdUERJ, 2012.

11 Além da obra de Feyerabend, remetemos os interessados ao artigo de ARAUJO; MENDONÇA; VIDEIRA, op. cit.

12 NICKLES, Thomas. Philosophy of science and history of science. Osiris, 10: 139-163, p. 140, 1995.

13 Ibid.

14 Os quatro princípios do Programa Forte são: 1) causalidade; 2) imparcialidade; 3) simetria; e 4) reflexividade. 0 mais controvertido talvez seja o princípio da simetria, segundo 0 qual a verdade e 0 erro podem ser explicados de maneira igualmente racional; todavia o princípio da reflexividade também gera polêmicas, dado que o que vale para a ciência deve ser eficiente também para a Sociologia da ciência. Pelo princípio de da causalidade, a Sociologia da ciência deve ser causal, preocupando-se com as condições que ocasionam a ciência, o que não exclui outros tipos de causas, além das sociais; e, pelo princípio da imparcialidade, para ser coerente, a Sociologia deve ser imparcial, não emitindo qualquer juízo de valor.

15 BROWN, James (Ed.). Scientific rationality: The sociological turn. Dordrecht: D. Reidel Publishing Company, 1984. p. 3.

16 GODFREY-SMITH, Peter. Theory and reality: An introduction to the philosophy of science. Chicago: The University of Chicago Press, 2003, p. 144.

17 Cf. MENDONÇA, op. cit., 2008.

18 PESTRE, Dominique. Thirty years of science studies: knowledge, society and the political. History and technology, v. 20, n. 4, p. 351, dez. 2004.

19 MENDONÇA; VIDEIRA, op. cit., 2004, p. 150.

20 DASTON, Lorraine (Org.). Biographies of scientific objects. Chicago: The University of Chicago Press, 2000. p. 2.

21 Idem, ibidem, p. 1-6

22 GALISON, Peter. Culturas etéreas e culturas materiais. In: GIL, F. (Org.). A ciência tal qual se faz. Lisboa: Edições João Sá da Costa, 1999. p. 398.

23 FEYERABEND, Paul. Matando o tempo: uma autobiografia. Tradução de Raul Fiker. São Paulo: Editora UNESP, 1996. p. 159, grifos do autor.

24 SAID, Edward. Culture and imperialism. Nova lorque: Vintage Books/Random House, 1993, p. xxv.

25 NICKLES, op. cit., p. 141.

26 Cf. MENDONÇA; VIDEIRA, op. cit., 2011, p. 233-243.

27 Cf. ARAUJO; MENDONÇA; VIDEIRA, op. cit., p. 50.

28 Cf. PESTRE, op. cit., p. 352.

29 MENDONÇA, op. cit., p. 210.

30 FEYERABEND, op. cit., 2010, p. 25. 

o legado de Aaron Swartz" e "Swartz e a sociedade de controle em rede: um debate brasileiro". Disponível em: < http://rafazanatta.blogspot.com.br/>. DEAR, Peter. Historiography of not-so-recent science. Hist. Sci., 1, p. 204-5, 2012.

33 NICOLELIS, Miguel et al. A brain-to-brain interface for real-time sharing of sesorimotor information. Scientific Reports. 28 de fevereiro de 2013.

34 Cf. MENDONÇA; VIDEIRA, op. cit., 2011, p. 241.

35 Uma boa síntese da posição nacional-desenvolvimentista e sua crítica podem ser encontradas em NEGRI, Antonio; COCCO, Giuseppe. Glob(AL): biopoder e luta em uma américa latina globalizada. Tradução de Eliana Aguiar. São Paulo: Record, 2005. p. 63-114.

36 COCCO, Giuseppe; GALVÃO, Alexander Patez; SILVA, Gerardo (Org.). Capitalismo cognitivo: trabalho, redes, inovação. Tradução de Eliana Aguiar. Rio de Janeiro: DP\&A, 2003.

37 FEYERABEND, Paul. A conquista da abundância. Tradução de Cecilia Prada e Marcelo Rouanet. São Leopoldo/RS: Editora Unisinos, 2006.

38 GOVERNO FEDERAL. Plano Brasil Maior. Disponível em: <http://www.brasilmaior.mdic.gov.br/ conteudo/128>.

39 FEYERABEND, Paul. Adeus à razão. Tradução de Vera Joscelyne. São Paulo: Editora Unesp, 2010. p. 325.

40 SOUZA, Jessé. Os batalhadores brasileiros: nova classe média ou nova classe trabalhadora? 2. ed. Belo Horizonte: UFMG, 2012. p. 357-361.

41 Breve história da formação da copesquisa (conricerca em italiano) em CAVA, Bruno. A copesquisa militante no autonomismo operaísta. Revista Lugar Comum, Rio de Janeiro, v. 37-38, p. 17-38, jan. 2013. Disponível em: <http://uninomade.net/lugarcomum/37-38/>. Para uma síntese histórica do operaísmo italiano, cf. ALTAMIRA, César. Os marxismos do novo século. Tradução de Leonora Corsini. Rio de Janeiro: Civilização Brasileira, 2008, Capítulo 2: 0 operaísmo italiano.

42 Cf., por exemplo, LATOUR, Bruno. Jamais fomos modernos. Tradução de Carlos Irineu da Costa. Rio de Janeiro: Editora 34, 1994; Idem. Reassembling the social. An introduction to actor-network-theory. Oxford: Oxford University Press, 2005.

43 ROGGERO, Gigi. La produzione del sapere vivo. Crisi dell'università e trasformazione del lavoro tra le due sponde dell'Atlantico. Verona: ombre corte, 2009. p. 112-117.

44 FEYERABEND, op. cit., 2010, p. 22.

45 VIVEIROS DE CASTRO, Eduardo. Métaphysiques cannibales. Paris: PUF, 2009. p. $26-29$.

460 conceito de "trabalho vivo", de Karl Marx, define a qualidade da produção humana antes da captura pelo processo do capital e a métrica do mercado. Isto é, uma qualidade incomensurável à quantificação pelo valor, que a precede ontologicamente (e não apenas cronologicamente). 0 capital, trabalho morto que é, precisa vampirizar o trabalho vivo para reproduzir-se. 0 trabalho vivo lhe é externo e não pode ser por ele gerado. 0 trabalho vivo consiste na produção de vida no interior da cooperação social, ele só existe em relação, como criatividade difusa e imaginação em marcha. Nesse sentido, Gigi Roggero aproveita a noção de trabalho vivo para desenvolver o conceito de "saber vivo", que é justamente um saber gerado no bojo das redes cooperativas de produção, um saber que não se descola do viver mesmo, enquanto conjunto de relações sociais qualificadas pela autovalorização e diferenciação. Cf. MARX, Karl. Grundrisse. Manuscritos econômicos de 1857-1858. Esboços da crítica da economia política. Tradução de Mário Duayer e Nélio Schneider. São Paulo: Boitempo, 2011. p. 230-248. Ver também ROGGERO, op. cit., p. 71-93; e CAVA, Bruno. Crítica do valor em tempos de megamáquinas. Universidade Nômade Itália, 23/10/2012. Disponível em: < http://www.uninomade.org/critica-do-valor-em-tempos-de-megamaquinas/> .

47 VIVEIROS DE CASTRO, Eduardo. Desenvolvimento econômico e reenvolvimento cosmopolítico: da necessidade extensiva à suficiência intensiva. Revista Sopro, v. 51, maio 2011. Disponível em: <http://culturaebarbarie.org/sopro/outros/suficiencia.html >.

48 FOUCAULT, Michel. Dits et Ecrits. Paris: Gallimard, 1994. v. IV, p. 578.

49 FOUCAULT, Michel. A ordem do discurso. Aula inaugural no Collège de France pronunciada em 2 de dezembro de 1970. Tradução de Laura Fraga de Almeida Sampaio. 11. ed. São Paulo: Loyola, 2004. A noção de autonomia das tradições científicas e não científicas em Feyerabend parece também um caminho possível para a aproximação proposta neste artigo. Em relação a essa questão, além da obra de Feyerabend, cf. ARAUJO; MENDONÇA; VIDEIRA, op. cit.

50 Essa indissociabilidade de pesquisa, organização política e autonomia produtiva é o grande ensinamento do livro clássico sobre copesquisa: ALQUATI, op. cit. Nesse ponto também vislumbramos uma aproximação com os science studies, sobretudo com Latour e a já mencionada teoria ator-rede. Cf. LATOUR, op. cit., 1994; 2005.

51 MARX, op. cit., p. 229-230.

52 Idem, ibidem.

[Recebido em Maio de 2013. Aprovado para publicação em Julho de 2013] 